OPEN ACCESS

Edited by:

Andrew Clayton

Swinburne University of Technology,

Australia

Reviewed by:

Francisco Solano

Universidad de Murcia, Spain

Wen Yi,

Zhejiang University, China

*Correspondence:

Alexander Carreño

alexander.carreno@unab.cl

Ramiro Arratia-Pérez

rarratia@unab.c

Carolina Otero

maria.otero@unab.c

Specialty section:

This article was submitted to

Chemical Biology,

a section of the journal

Frontiers in Chemistry

Received: 12 April 2018

Accepted: 23 July 2018

Published: 15 August 2018

Citation:

Llancalahuen FM, Fuentes JA,

Carreño A, Zúñiga $C$,

Páez-Hernández D, Gacitúa M,

Polanco $R$, Preite MD, Arratia-Pérez $R$ and Otero $C$ (2018) New Properties of a Bioinspired Pyridine Benzimidazole

Compound as a Novel Differential Staining Agent for Endoplasmic Reticulum and Golgi Apparatus in Fluorescence Live Cell Imaging. Front. Chem. 6:345 doi: 10.3389/fchem.2018.00345

\section{New Properties of a Bioinspired Pyridine Benzimidazole Compound as a Novel Differential Staining Agent for Endoplasmic Reticulum and Golgi Apparatus in Fluorescence Live Cell Imaging}

Felipe M. Llancalahuen ${ }^{1}$, Juan A. Fuentes ${ }^{2}$, Alexander Carreño ${ }^{3,4 *}$, César Zúñiga ${ }^{3}$, Dayán Páez-Hernández ${ }^{3}$, Manuel Gacitúa ${ }^{5}$, Rubén Polanco ${ }^{6}$, Marcelo D. Preite ${ }^{7}$, Ramiro Arratia-Pérez ${ }^{3 *}$ and Carolina Otero ${ }^{1 *}$

${ }^{1}$ Escuela de Química y Farmacia, Facultad de Medicina, Universidad Andres Bello, Santiago, Chile, ${ }^{2}$ Laboratorio de Patogénesis y Genética Bacteriana, Facultad de Ciencias de la Vida, Universidad Andres Bello, Santiago, Chile, ${ }^{3}$ Center of Applied Nanosciences, Universidad Andres Bello, Santiago, Chile, ${ }^{4}$ Fondo Nacional de Ciencia y Tecnología (FONDECYT), Santiago, Chile, ${ }^{5}$ Facultad de Química y Biología, USACH, Santiago, Chile, ${ }^{6}$ Centro de Biotecnología Vegeta, Facultad de Ciencias de la Vida, Universidad Andres Bello, Santiago, Chile, ${ }^{7}$ Departamento de Química Orgánica, Facultad de Química, Pontificia Universidad Católica de Chile, Santiago, Chile

In this study, we explored new properties of the bioinspired pyridine benzimidazole compound B2 (2,4-di-tert-butyl-6-(3H-imidazo[4,5-c]pyridine-2-yl)phenol) regarding its potential use as a differential biomarker. For that, we performed 1D ${ }^{1} \mathrm{HNMR}$ (TOCSY), UV-Vis absorption spectra in different organic solvents, voltammetry profile (including a scan-rate study), and TD-DFT calculations that including NBO analyses, to provide valuable information about B2 structure and luminescence. In our study, we found that the B2 structure is highly stable, where the presence of an intramolecular hydrogen bond $(\mathrm{IHB})$ seems to have a crucial role in the stability of luminescence, and its emission can be assigned as fluorescence. In fact, we found that the relatively large Stokes Shift observed for B2 (around $175 \mathrm{~nm}$ ) may be attributed to the stability of the $\mathbf{B} 2$ geometry and the strength of its $\mathrm{IHB}$. On the other hand, we determined that B2 is biocompatible by cytotoxicity experiments in HeLa cells, an epithelial cell line. Furthermore, in cellular assays we found that $\mathbf{B 2}$ could be internalized by passive diffusion in absence of artificial permeabilization at short incubation times (15 min to $30 \mathrm{~min}$ ). Fluorescence microscopy studies confirmed that B2 accumulates in the endoplasmic reticulum (ER) and Golgi apparatus, two organelles involved in the secretory pathway. Finally, we determined that B2 exhibited no noticeable blinking or bleaching after $1 \mathrm{~h}$ of continuous exposure. Thus, B2 provides a biocompatible, rapid, simple, and efficient way to fluorescently label particular organelles, producing similar results to that obtained with other well-established but more complex methods.

Keywords: benzimidazole, fluorescence, hydrogen bond, differential staining, endoplasmic reticulum, Golgi apparatus 


\section{INTRODUCTION}

The capability to distinguish and identify different subcellular compartments is critical for understanding organelle function, biogenesis, and cell maintenance, as well as for describing protein sorting and intracellular trafficking pathways (Watson et al., 2005). To this end, cell imaging is becoming a powerful tool to reveal particular biological structures, and even molecular mechanisms, unraveling dynamics and functions of many cellular processes. Accordingly, the development of diverse transmitted light microscopy approaches, including fluorescence microscopy, is increasingly contributing to improve this technique. In this context, the research of new, improved fluorescent indicators clearly constitutes a challenge (Sanderson et al., 2014; Wollman et al., 2015). One of the most desired properties of the fluorophores is their ability to differentially interact with discrete structures in the cell; to this end, the understanding of the chemical properties of these fluorophores is crucial in the design of this kind of molecules. Nowadays, most intracellular compartments can be detected by specific labeling through fluorophores conjugated to particular molecules, such as antibodies, which provide differential binding. For instance, endoplasmic reticulum (ER) and Golgi apparatus, two organelles that work together in the secretory pathway and protein sorting of eukaryotic organisms, which can be stained with fluorophores conjugated to either anti-protein disulfide isomerase (PDI) or anti-58K mouse monoclonal antibody, respectively (Bielaszewska et al., 2013, 2017; Cañas et al., 2016). Nevertheless, the use of antibodies is complex because it requires several steps, remarking the need of alternatives, such as transfection of gene fusions. These gene fusions harbor domains that are differentially sorted inside the cell fused with luminescent domains that allow their identifications via fluorescence microscopy. Although extensively used, transfection is a technique that requires a couple of days to be performed (Kingston et al., 2001). On the other hand, differential dyes have been reported for to specifically stain cellular organelles. In this sense, the organic dye $\mathrm{DiOC}_{6}$ (3) (3-hexyl-2-(3-(3-hexyl-2(3H)benzoxazolylidene)-1-propenyl)-iodide), a lipophilic, cationic, green fluorescent compound, has been used to specifically stain the ER (Sabnis et al., 1997, 2009). In addition, fluorescent analogs of ceramide have proved to be especially valuable for specifically labeling the Golgi apparatus, which receives, processes, and sorts newly synthesized proteins exported from the ER (Cooper, 2000). Although these dyes readily accumulate in the ER and in Golgi apparatus of most cell types by a preferential membrane partitioning process, both stains present biocompatibility problems, thereby they must be functionalized with bovine serum albumin (BSA), prolonging and complicating the staining protocol (Sabnis et al., 1997).

Recently, we demonstrated that 2,4-di-tert-butyl-6(3H-imidazo[4,5-c]pyridine-2-yl)phenol (B2), a neutral benzimidazole derivate exhibiting an intramolecular hydrogen bond (IHB). B2 shows luminescent emission at room temperature, with a large Stokes shift (i.e., $\lambda_{\mathrm{ex}}=335 \mathrm{~nm} ; \lambda_{\mathrm{em}}=$ $510 \mathrm{~nm}$ in acetonitrile) (Carreño et al., 2016). Furthermore, B2 has proved to efficiently stain free bacteria (i.e., Salmonella enterica and Escherichia coli), biofilms of Lactobacillus kunkei and L. rhamnosus, and epithelial cell lines (SKOV-3 and HEK293), as assessed by confocal microscopy (Carreño et al., 2016; Berríos et al., 2017). Interestingly, when epithelial cells were observed, we distinguished a punctuated pattern, apparently located in the cytoplasm. These results strongly suggest that B2 is differentially staining a particular structure/organelle in those cells. Thus, in this work we explored the potential use of $\mathbf{B 2}$ as a differential, antibody-free fluorophore in epithelial cells. To this purpose, we performed studies aimed to characterize its optical and electrochemical features, to better understand the role of the intramolecular hydrogen bond in the luminescent properties of $\mathbf{B 2}$. To support experimental findings, we also performed computational calculations using DFT theory. In addition, we found that $\mathbf{B 2}$ is a biocompatible molecule that generates a punctuate pattern in an epithelial cell line (HeLa). Furthermore, we found that B2 uptake can be detected at short incubation times, apparently by passive a diffusion mechanism. Finally, we found that B2 provides a rapid $(30 \mathrm{~min}$ ), simple (no cell permeabilization is required), biocompatible, and efficient way to fluorescently label both ER and Golgi apparatus, producing similar results to that obtained with other well-established methods. We also provide evidence that $\mathbf{B} \mathbf{2}$ is a good candidate to be used as a new, differential, antibody-free fluorophore for organelles belonging to the cell secretory pathway, in time-lapse experiments or short videos with continuous exposure, even at low temperatures.

\section{MATERIALS AND METHODS}

All chemicals and solvents were purchased from Merck or Aldrich and used without further purification. All solvents were stored over appropriate molecular sieves prior to use.

\section{Synthesis of 2,4-di-tert-butyl-6-(3H- imidazo[4,5-C]pyridine-2-YL)phenol (B2)}

The general procedure for the synthesis was previously reported, (Carreño et al., 2016) obtaining around $40 \%$ yield. Melting point: $311-312^{\circ} \mathrm{C}$. FTIR (ATR, $\mathrm{cm}^{-1}$ ): $2961(\mathrm{vOH}), 2904$ and 2868 $(\nu N H), 1626(\nu \mathrm{Ce}=\mathrm{N}), 1526(\nu \mathrm{C}=\mathrm{C}) .{ }^{1} \mathrm{HNMR}(400 \mathrm{MHz}$, DMSO- $\left._{\mathrm{d} 6}, \mathrm{ppm}\right): \delta=1.33$ [s; 9H; tBu]; $1.43[\mathrm{~s} ; 9 \mathrm{H} ; \mathrm{tBu}] ; 7.40$ [d, $\mathrm{J}=1.9 \mathrm{~Hz} ; 1 \mathrm{H} ; \mathrm{H} 5], 7.69$ [d; $J=4.7 \mathrm{~Hz} ; 1 \mathrm{H} ; \mathrm{H} 2], 8.02[\mathrm{~s} ; 1 \mathrm{H} ; \mathrm{H} 4]$, 8.36 [d; J = 5.3 Hz; 1H; H1], 8.99 [s; 1H; H3], 13.60[s; 1H; O-H]. UV/VIS: (chloroform, room temperature) $\lambda \mathrm{nm}\left(\varepsilon \mathrm{mol}^{-1} \mathrm{dm}^{3}\right.$ $\left.\mathrm{cm}^{-1}\right)$ : $332\left(13.32 \times 10^{3}\right), 294\left(19.09 \times 10^{3}\right), 284\left(15.51 \times 10^{3}\right)$; (acetonitrile, room temperature) $\lambda \mathrm{nm}\left(\varepsilon \mathrm{mol}^{-1} \mathrm{dm}^{3} \mathrm{~cm}^{-1}\right): 327$ $\left(12.91 \times 10^{3}\right), 292\left(18.67 \times 10^{3}\right), 282\left(14.88 \times 10^{3}\right) ;($ DMSO, room temperature) $\lambda \mathrm{nm}\left(\varepsilon \mathrm{mol}^{-1} \mathrm{dm}^{3} \mathrm{~cm}^{-1}\right): 332(11.30 \times$ $\left.10^{3}\right), 294\left(15.44 \times 10^{3}\right), 284\left(12.23 \times 10^{3}\right)$. Rf: 0.38 (ethylacetate as solvent).

\section{Physical Measurements}

NMR spectra were recorded on a Bruker AVANCE 400 spectrometer operating at $400 \mathrm{MHz}$, at $25^{\circ} \mathrm{C}$. Samples were 
dissolved in deuterated dimethyl sulfoxide (DMSO-d6), using tetramethylsilane as internal standard. FTIR techniques were recorded in an UATR spectrum Two Perkin Elmer spectrophotometer.

Purity of B2 was checked by TLC using glass plates precoated with SiliaPlate TLC Aluminum foil TLC were supplied by Silicycle as stationary phase, and a suitable solvent system was used as mobile phase (ethyl acetate). Spots were visualized with short wave ultraviolet light $(\lambda=254 \mathrm{~nm})$ using Spectroline LongLife TM Filter. Melting points were determined on a Stuart 10 Scientific melting point apparatus SMP3 (UK) in open capillary tubes.

For electrochemical experiments, a working solution containing $0.01 \mathrm{~mol} / \mathrm{L}$ of the respective compound together with $0.1 \mathrm{~mol} / \mathrm{L}$ tetrabutylammonium hexafluorophosphate $\left(\mathrm{TBAPF}_{6}\right)$ as supporting electrolyte in $\mathrm{CH}_{3} \mathrm{CN}$, was used. Prior to each experiment, the working solution was purged with high purity argon, and an argon atmosphere was maintained during the whole experiment. A polycrystalline non-annealed platinum disc (2 $\mathrm{mm}$ diameter) was used as working electrode. A platinum gauze of large geometrical area, separated from the cell main compartment by a fine sintered glass, was used as counter electrode. All potentials quoted in this work were referred to an $\mathrm{Ag} / \mathrm{AgCl}$ electrode in tetramethylammonium chloride to match the potential of a saturated calomel electrode (SCE), at room temperature. All electrochemical experiments were performed at room temperature on a $\mathrm{CHI} 900 \mathrm{~B}$ bipotentiostat interfaced to a PC running the CHI 9.12 software that allowed experimental control and data acquisition.

\section{${ }^{1} \mathrm{H}-\mathrm{NMR}$ and Ftir Characterization of B2}

${ }^{1} \mathrm{H}-\mathrm{NMR}$ and FTIR techniques were performed as previously described for B2 (Carreño et al., 2016). These techniques were used to confirm the correct synthesis of $\mathbf{B 2}$.

\section{Computational Details}

All structural and electronic properties were obtained using the Amsterdam Density Functional (ADF) code (Te Velde et al., 2001). All molecular structures were fully optimized by an analytical energy gradient method as implemented by Verluis and Ziegler (Echeverria et al., 2009; Ramírez-Tagle et al., 2010; Alvarado-Soto and Ramirez-Tagle, 2015; Bjorgaard et al., 2015), using the hybrid B3LYP functional and the standard Slatertype-orbital (STO) basis set with triple- $\zeta$ quality double plus polarization functions (TZ2P) for all the atoms (Rabanal-Leon et al., 2014; Zhang et al., 2016). Frequency analyses were performed after the geometry optimization to corroborate the minimum and to compare with experimental infrared spectra. Natural bond orbital (NBO) analysis was used to characterize energies of the IHB (Avilés-Moreno et al., 2017; Guajardo Maturana et al., 2017). Time-dependent density functional theory (TDDFT) (Ghane et al., 2012; Fuks et al., 2013; Mosquera and Wasserman, 2015), used at the same level of theory to calculate the excitation energies using in all cases the conductor-like screening model for realistic solvents (COSMO) (Sinnecker et al., 2006; Simpson et al., 2015; Yamin et al.,
2016), DMSO to estimate the hydrogen bond stability and to visualize the conformational changes due to the solvent polarity, additionally the calculations were also performed in the gas phase (Tsolakidis and Kaxiras, 2005; Quartarolo and Russo, 2011).

\section{Cell Culture}

The HeLa cell line (ATCC ${ }^{\circledR}$ CCL-2 ${ }^{\mathrm{TM}}$ ) (cervical adenocarcinoma) was grown in $25 \mathrm{~cm}^{2}$ polystyrene bottles in Dulbecco's High Glucose Modified Eagle Medium (DMEM) supplemented with $10 \% \mathrm{v} / \mathrm{v}$ fetal serum bovine (FBS), $1 \mathrm{mM}$ sodium pyruvate and $1 \% \mathrm{v} / \mathrm{v}$ penicillin-streptomycin. Cells were incubated at $37^{\circ} \mathrm{C}$ and $5 \% \mathrm{CO}_{2}$, changing the culture medium every 2-3 days, and propagated when they reached between 80 and $90 \%$ confluence.

\section{Cellular Staining}

HeLa cells were seeded in a 24 -well culture dish $\left(3 \times 10^{5}\right.$ cells per well) in which a $12-\mathrm{mm}$ diameter coverslip was previously added, and allowed to acclimate for $24 \mathrm{~h}$. Each well was then washed 3 times with sterile $1 \times \mathrm{PBS}$ and then the different concentrations of B2 $(200,100,50,25$, or $12.5 \mu \mathrm{g} / \mathrm{mL})$ and DMSO vehicle (50, 25, $12.5,6.125$, and $3.0625 \%$ ) were added to each well and incubated for 15 and $30 \mathrm{~min}$ at $37^{\circ} \mathrm{C}$ with $5 \% \mathrm{CO}_{2}$. It is important to underline that permeabilization procedures are not necessary. Subsequently, each well was washed 3 times with sterile $1 \times$ PBS and coverslips were deposited on the slides using $5 \mu \mathrm{l}$ of Fluoromount ${ }^{\circledR}$ mounting medium. Each slide was left to dry in the dark at room temperature overnight and were sealed with acrylic paint.

\section{Fluorescence Microscopy}

The analysis was performed on a Model BX61 Fluorescence Microscope (Olympus Corp., Tokyo, Japan), Spinning Disk Olympus (DSU) system, coupled to an ORCA-R2 camera (Hamamatsu Photonics KK, Japan) and CellSens Dimension software v1.9 (Olympus Corp., Tokyo, Japan). Fluorescence emission was obtained by excitation with a xenon lamp. Emission was collected with a DAPI filter (450 to $500 \mathrm{~nm}$ ).

\section{B2 Cellular Uptake}

HeLa cells $\left(2 \times 10^{5}\right.$ cells/well $)$ were seeded in 24 -well plates and incubated for $24 \mathrm{~h}$. To evaluate the cellular uptake of compound B2, concentrations of $25 \mu \mathrm{g} / \mathrm{mL}$ and $50 \mu \mathrm{g} / \mathrm{mL}$ were prepared in culture medium, added to each well and incubated for 15 and $30 \mathrm{~min}$. In addition, to evaluate whether the uptake of $\mathbf{B} 2$ depends on energy, cells were incubated with the same treatments at $4^{\circ} \mathrm{C}$, a temperature where no endocytic processes occur (Mukherjee et al., 1997).

After the incubation time, cells were washed 3 times with $1 \times$ PBS and peeled off the culture plate using a $0.2 \% \mathrm{w} / \mathrm{v}$ PBSEDTA solution and incubated for $20 \mathrm{~min}$ at RT. Suspended cells were washed twice with FACS buffer (2\% PBS supplemented with fetal bovine serum) and resuspended in $500 \mu \mathrm{l}$ PBS. Finally, the fluorescence intensity of the cells was quantified through a BD Accuri $^{\text {TM }}$ FACSARIA II flow cytometer using the FlowJo 7.6.1 software. 


\section{Cell Viability Assays}

HeLa cells were cultured in Dulbecco's Modified Eagle's Medium (DMEM) containing 10\% fetal bovine serum (FBS), $2 \mathrm{mM}$ L-glutamine, 100 units $/ \mathrm{mL}$ penicillin and $100 \mu \mathrm{g} / \mathrm{mL}$ streptomycin. Cells were maintained in $75 \mathrm{~cm}^{2}$ flasks in a $5 \% \mathrm{CO}_{2}$-humidified atmosphere at $37^{\circ} \mathrm{C}$. Passage took place every 2-3 days. All cell culture supplies were purchased from Sigma-Aldrich. Toxicity was determined using the 3-(4,5dimethylthiazol-2-yl)-2,5- diphenyltetrazolium bromide (MTT) cell viability assay after $15 \mathrm{~min}, 30 \mathrm{~min}, 1 \mathrm{~h}$, and $24 \mathrm{~h}$ of incubation with B2. MTT is a yellow compound that, when reduced by active mitochondria, produces purple formazan crystals that can be measured spectrophotometrically (Low et al., 2016; Sheikh et al., 2016). For this purpose, MTT (Sigma-Aldrich) was dissolved in phosphate buffered saline (PBS) to a concentration of $5 \mathrm{mg} / \mathrm{mL}$ and further diluted in culture medium (1:11). Cells were incubated with this MTTsolution for $4 \mathrm{~h}$ under normal culture conditions. Afterwards, $100 \mu \mathrm{L}$ of isopropyl alcohol were added. To completely dissolve the formazan salts, plates were incubated for $10 \mathrm{~min}$ on a shaker and quantified by measuring absorbance at $570 \mathrm{~nm}$ with an ELISA microplate reader. Cell viability was calculated as percentage of surviving cells compared to untreated control cells.

\section{Transformation of Chemically Competent TOP-10 Escherichia Coli}

For propagation of the desired vector, it was introduced into the chemically competent E. coli TOP10 (ThermoFisher) ${ }^{1}$ (generated according to the manufacturer's instructions). The transformation was performed using $100 \mu \mathrm{L}$ of the chemo-competent bacteria and $1 \mu \mathrm{g}$ of circular vector (KDEL-GFP or sialyl transferase signal anchor sequenceRFP). The mixture was incubated on ice for $30 \mathrm{~min}$ and a thermal shock was quickly performed at $42^{\circ} \mathrm{C}$ for $2 \mathrm{~min}$, immediately after, was put on ice for $3 \mathrm{~min}$ and $900 \mu \mathrm{L}$ of LB broth was added and incubated for $1 \mathrm{~h}$ at $37^{\circ} \mathrm{C}$. Finally, the bacteria were plated on LB agar supplemented with $50 \mu \mathrm{g} / \mathrm{mL}$ kanamycin for the selection of the transforming colonies.

\section{Cellular Transfection}

HeLa cells were seeded in a 24 -well culture dish $\left(5 \times 10^{5}\right.$ cells per well) in which a glass cover was previously added to each well and allowed to acclimate for $24 \mathrm{~h}$. Subsequently, the entire culture medium was removed, and each well was washed 3 times with sterile $1 \times$ PBS. The different combinations of DNA and Lipofectamine $3000^{\circledR}$ Transfection Reagent were performed according to the manufacturer's instructions. After all components were added to the cell culture (Lipofectamine $300{ }^{\circledR}$ Transfection Reagent, DNA and DMEM medium), it was incubated for $6 \mathrm{~h}$ at $37^{\circ} \mathrm{C}$ with $5 \% \mathrm{CO}_{2}$. The content of each well was removed and washed 3 times with $1 \times$

\footnotetext{
${ }^{1}$ Thermofisher ER-Tracker $^{T M}$ Red (BODIPYTM TR Glibenclamide), for LiveCell Imaging [Online]. Available online at: http://www.thermofisher.com/order/ catalog/product/E34250 [Accessed].
}

sterile PBS. Then, $500 \mu \mathrm{L}$ of complete DMEM medium was added to each well and incubated until $48 \mathrm{~h}$ of treatment were completed. Finally, cell transfection was checked using an inverted-light microscope and a BX-53 epifluorescence microscope.

\section{Co-localization Assays}

HeLa cells were seeded in a 24 -well culture dish with $5 \times$ $10^{5}$ cells per well in which a $12-\mathrm{mm}$ diameter coverslip was previously added and allowed to acclimate for $24 \mathrm{~h}$. Cells were then transfected with the KDEL-GFP and Sialyl-RFP plasmids, which express specific fluorescent peptide of the endoplasmic reticulum and Golgi apparatus, respectively. After the transfection process was completed, each well was washed 3 times with sterile $1 \times$ PBS and then the different concentrations of B2 $(25 \mu \mathrm{g} / \mathrm{mL}$ and $50 \mu \mathrm{g} / \mathrm{mL})$ and the percentages of vehicle DMSO (12.5 and 6.125\%) were added for $15 \mathrm{~min}$ with $5 \%$ $\mathrm{CO}_{2}$ and at $37^{\circ} \mathrm{C}$. Each well was then washed 3 times with sterile $1 \times$ PBS and fixed for $5 \mathrm{~min}$ with $4 \%$ PFA in PBS (4g PFA, $1 \mathrm{M} \mathrm{CaCl}_{2}, 1 \mathrm{M} \mathrm{MgCl}_{2}, \mathrm{pH} 7.4$ adjusted solution), washed 3 times with PBS and each coverslip was mounted on slides using $5 \mu \mathrm{l}$ of Electron Microscopy Sciences. Each slide was allowed to dry in the dark at room temperature overnight and then sealed with acrylic paint. Finally, all samples were observed using the Olympus BX-61-DSU epifluorescence microscope.

\section{Statistical Analysis}

All values of analyzed data are presented as mean standard error (SE) from three biological replicates. Statistical analysis included was one-way ANOVA followed by multiple comparison test (Tukey). Differences among groups were considered statistically significant when $p<0.05$.

\section{RESULTS AND DISCUSSION}

\section{B2 Characterization}

B2 (Figure S1, see Table S1 for characteristic constants) is insoluble in water, but presents low solubility in chloroform, acetonitrile and methanol, and a good solubility in DMSO at room temperature. B2 synthesis was confirmed by their FTIR (Figures S2, S3), ${ }^{1} \mathrm{H}-$ NMR spectra (for proton numbering, see Figure S4; for ${ }^{1} \mathrm{H}-\mathrm{NMR}$ see Figure S5) including TOCSY experiments (Figure S6-S8).

Since B2 is being tested as a new fluorophore for biological applications, its use in different solvents may be also desirable. In this context, electronic absorption spectra of B2 were measured in different organic solvents: chloroform, acetonitrile, and DMSO, at room temperature. We observed three intense absorption bands. The first two high-intensity absorption can be assigned to $n \rightarrow \pi^{*}(-\mathrm{C}=\mathrm{N}-)$ and $\pi \rightarrow \pi^{*}$ transitions, respectively. No significant shifts were observed for $\mathbf{B} 2$ in the different solvents used (see Table S2), suggesting that the IHB in $\mathbf{B} 2$ is stable under all the tested conditions, even in presence of DMSO, which can form hydrogen bonds with the solute. 
Any change in the $\mathbf{B} 2$ structure (including dissociation of the IHB), produced by interaction with the solvent, would lead to changes in the absorption spectra. This was not observed for B2 under the tested conditions (see Figure S9 for UV-Vis spectrum).

To complement the previously reported electrochemical characterization of B2 (Carreño et al., 2016), a scan-rate study was performed at 50,200, and $400 \mathrm{mVs}^{-1}$. We found that B2 exhibited a single reversible reduction process $\left[\operatorname{Red}_{(\mathrm{rev})}^{\mathrm{I}}\right]$ at $-0.84 \mathrm{~V}$, and two irreversible oxidations, $\mathrm{Ox}_{(\mathrm{irr})}^{\mathrm{I}}$ and $\mathrm{Ox}_{(\mathrm{irr})}^{\mathrm{II}}$, at 0.96 and $1.47 \mathrm{~V}$ vs. SCE (saturated calomel electrode), respectively, consistent to previously reported data (Carreño et al., 2016). As inferred from the Figure S10, the control mechanism for all the studied processes depends on the species diffusion from the bulk solution (see Table S3). Diffusional control of red-ox processes has been reported for similar benzimidazoles and other bioinspired compounds (Savarino et al., 1997; Boiani et al., 2006; Moore et al., 2008; Manbeck et al., 2016), but the reduction in those cases has been found to be irreversible. The difference is that $\mathbf{B} 2$ possesses an IHB that has been attributed to stabilize the radical form, explaining the reversibility of reduction and emphasizing the importance of the IHB in the $\mathbf{B} 2$ features (Benisvy et al., 2006; Moore et al., 2010).

\section{Theoretical Calculations}

As stated, B2 is a luminescent compound (Carreño et al., 2016). To better characterize this phenomenon, we performed timedependent density functional theory (TDDFT) calculations to assign the electronic transitions. The first step was to optimize the ground $\left(\mathrm{S}_{0}\right)$ and the first excited singlet state $\left(\mathrm{S}_{1}\right)$; in a second step, absorption and emission bands were calculated using TDDFT. All the calculations where performed using COSMO model for solvent with the parameters of DMSO (Liu et al., 2011). We found that the geometry of $S_{0}$ and $S_{1}$ exhibited no significant differences, showing, in both cases, that the structure must remain planar, most likely due to the presence of the IHB (see Table S4). To further study the B2 IHB, we evaluated the second-order interaction energy by calculating natural bond orbitals $(\mathrm{NBO})$. We found that the IHB energy is $6.23 \mathrm{kcal} / \mathrm{mol}$ for $\mathrm{S}_{0}$, and $6.13 \mathrm{kcal} / \mathrm{mol}$ for $\mathrm{S}_{1}$. These values are in agreement with the reported values in similar compounds harboring IHB (Muhammad et al., 2010; Abdel Ghani and Mansour, 2012; Monajjemi, 2012; Carreño et al., 2016; Yankova and Radev, 2016), and support the stability of this interaction (Sosa et al., 2002). In this sense, the experimental UVvis results (see Table S2) were corroborated by computational methods (see and Figure S9). To further characterize the UVvis observed transitions, TDDFT calculations were conducted (see Table S5). This calculated transition is composed of a $\mathrm{HOMO}-2 \rightarrow$ LUMO $+1\left(\mathrm{n} \rightarrow \pi^{*}\right), \mathrm{HOMO}-1 \rightarrow \operatorname{LUMO}(\pi \rightarrow$ $\left.\pi^{*}\right)$, and $\mathrm{HOMO} \rightarrow \operatorname{LUMO}\left(\pi \rightarrow \pi^{*}\right)$. The band located experimentally at $332 \mathrm{~nm}$ (DMSO), theoretically calculated at $339 \mathrm{~nm}$, corresponded to a $\mathrm{HOMO} \rightarrow$ LUMO transition. Both the HOMO and LUMO composition involves the IHB (Figure 1). The isosurfaces provide some suggestions regarding experimental results obtained from UV-Vis studies (see Table S2 and Figure S9). All these results together demonstrate the stability of the IHB in $\mathbf{B 2}$.

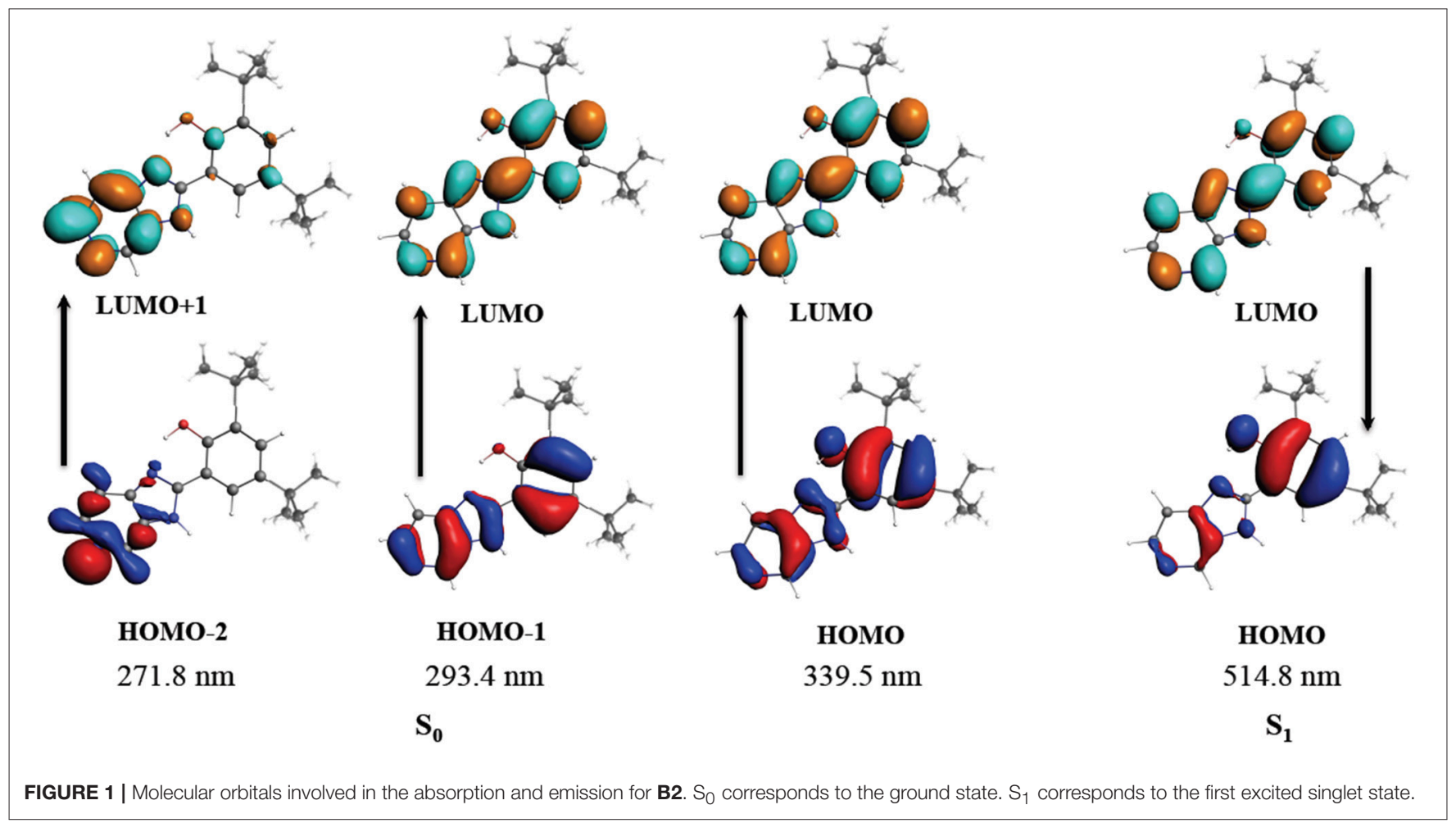


On the other hand, the emission band was calculated using the geometry of the first excited state $S_{1}$ to perform a TDDFT calculation. The emission was calculated as a $\pi^{*} \rightarrow \pi$ between LUMO and HOMO orbitals at $515 \mathrm{~nm}$, in good agreement with the experimental value reported around $500 \mathrm{~nm}$ (data not shown) (Carreño et al., 2016). As stated above, HOMO and LUMO composition involves the IHB, reinforcing the contribution of this interaction in the stability of $\mathbf{B 2}$. The rigidity of the $\mathbf{B} 2$ structure substantially reduces the vibronic relaxation, explaining the luminescence of this compound, as reported for other molecules (Gopal et al., 1995). Regarding the luminescence of B2, the geometry of the first excited triplet was also calculated and used for a TDDFT calculation using a previously described protocol (Carreño et al., 2017). However the contribution of the triplet to the emission band was less than $0.5 \%$, indicating that the emission can be assigned to fluorescence, as previously suggested (Carreño et al., 2016). Altogether, the combined information obtained by the analyses described above, provides valuable information about B2 structure, and its luminescence.

\section{Cellular Studies}

To further characterize B2 in cellular assays, we stained HeLa cells (epithelial cell line) with B2 (200, 100, 50, 25, or $12.5 \mu \mathrm{g} / \mathrm{mL}$ ) for $30 \mathrm{~min}$, prior to fluorescent microscopy. Beforehand, we characterized the $\mathbf{B} 2$ staining properties using a confocal microscope, with laser excitation at $405 \mathrm{~nm}$, and emission collected with a long-pass filter in the range of 425 to $525 \mathrm{~nm}$ (Carreño et al., 2016). Although confocal microscopy exhibits several advantages, such as the possibility to examine samples through the $Z$ axis, it needs special requirements. For that reason, this time we used a epifluorescence microscope, using a xenon lamp (excitation) and DAPI filter (emission, 450 to $500 \mathrm{~nm}$ ) (Atale et al., 2014). We found that B2 showed a suitable fluorescence inside cells, were the optimal concentration ranged between 25 and $50 \mu \mathrm{g} / \mathrm{mL}$ of B2 (Figure 2). When $12.5 \mu \mathrm{g} / \mathrm{mL}$ B2 was used, we were unable to observe fluorescence under the tested conditions (data not shown). Interestingly, we observed that B2 produced a punctuate pattern inside cells (Figure 2), strongly suggesting that $\mathbf{B 2}$ is not a general, but a differential stain. In addition, it is important to remark that, albeit $30 \mathrm{~min}$ of

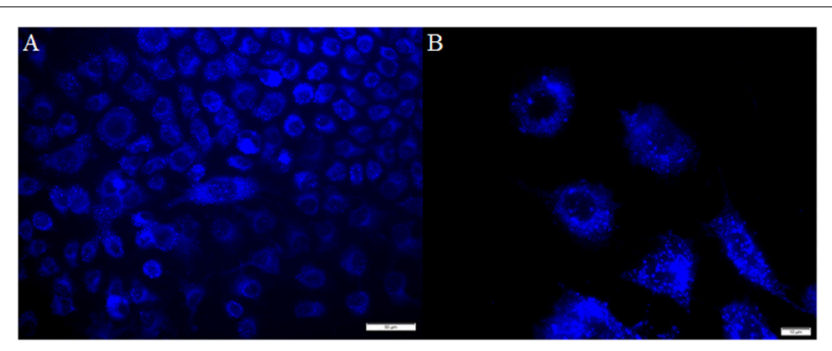

FIGURE 2 | Labeling pattern of B2. HeLa cells were seeded on coverslips and incubated with $50 \mu \mathrm{g} / \mathrm{mL}$ B2 for $30 \mathrm{~min}$ at $37^{\circ} \mathrm{C}$ prior being fixed and analyzed by fluorescence microscopy. Bar size $50 \mu \mathrm{m}$ (A) and $10 \mu \mathrm{m}$ (B). We found similar results with a shorter $\left(15 \mathrm{~min}\right.$ at $\left.37^{\circ} \mathrm{C}\right)$ incubation and/or with $25 \mu \mathrm{g} / \mathrm{mL}$ B2; albeit not staining was observed with $12.5 \mu \mathrm{g} / \mathrm{mL}$ B2 (data not shown). incubation with $\mathbf{B} 2$ are optimal, $15 \mathrm{~min}$ are sufficient to visualize cells under the fluorescence microscope (data not shown), highlighting the potential of this compound as a relatively quick biomarker, even using common equipment, such as a xenon or mercury lamp, and a DAPI filter. Moreover, it is clear from these experiments that chemical derivatizations are not required for $\mathbf{B} 2$ to be used as biomarker. Finally, the B2 staining protocol can be performed without the need of additional permeabilization steps, underlining its simplicity. In this sense, DMSO has been known to enhance cell membrane permeability of drugs or DNA. Studies exploring DMSO applicability to promote plasma membrane permeability using different molecules in living cells, demonstrated that DMSO can increase cell permeabilization, in a both concentration- and time-depending manner (de Ménorval et al., 2012). It has been reported that $10 \% \mathrm{v} / \mathrm{v}$ of DMSO slightly

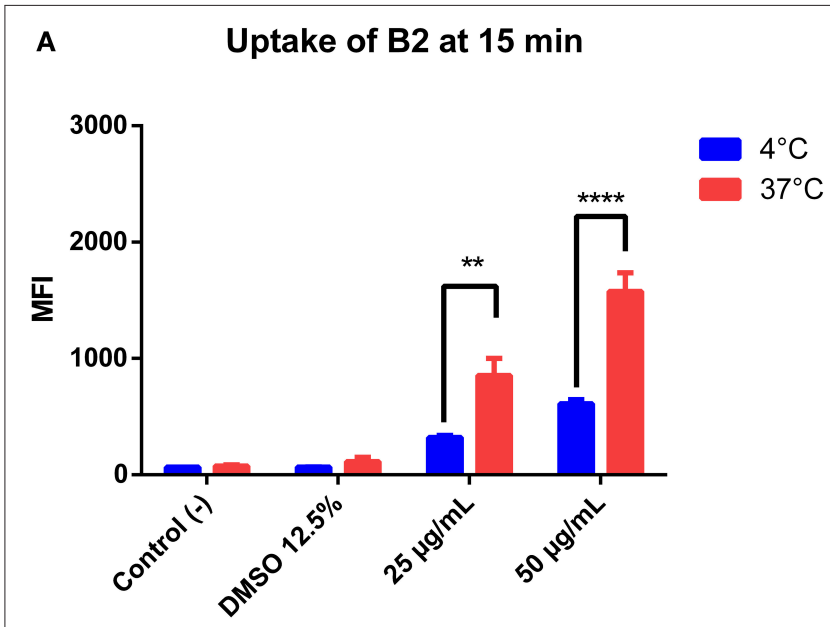

B

B Uptake of B2 at $30 \mathrm{~min}$

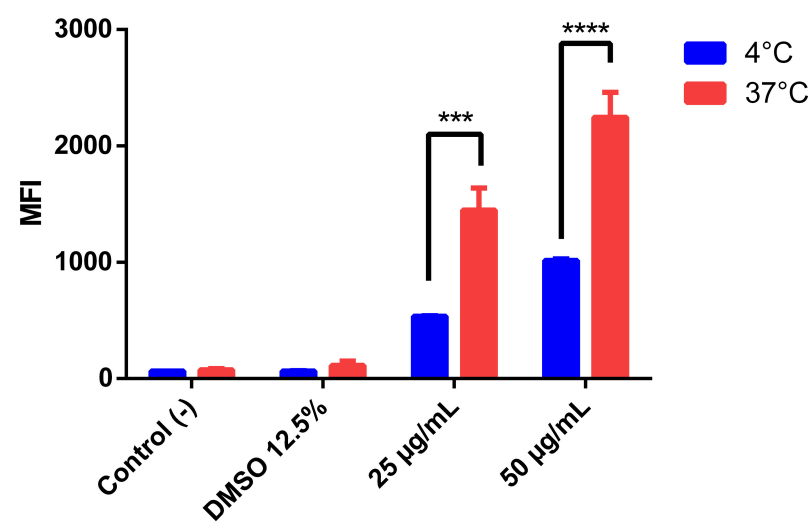

FIGURE 3 | Quantification of B2 uptake into HeLa cells. HeLa cells were incubated with different concentrations of $\mathbf{B 2}(25$ or $50 \mu \mathrm{g} / \mathrm{mL})$, at $4^{\circ} \mathrm{C}$ or $37^{\circ} \mathrm{C}$, for $15 \mathrm{~min}$ (A) or $30 \mathrm{~min}$ (B). The mean fluorescence intensity (MFI) was determined by flow cytometry using a 350-nm excitation laser and a 520-nm detector. The statistical difference is based on the negative control (culture medium alone). A 2-way ANOVA was performed with Tukey's posttest as a statistical analysis. Only relevant differences are depicted in the figure. ${ }^{\star \star} p<$ $0.01,{ }^{* \star *} p<0.001,{ }^{* \star \star *} p<0.0001 . n=3$ (biological triplicate). 
increase cell permeability after $1 \mathrm{~h}$ of incubation, but its impact in the entry of polar molecules is marginal, as assessed by the absence of swelling and the limited amount of water that could cross the plasma membrane. Although the presence of small undulations in the plasma membrane were reported in eukaryotic cells treated with $10 \%$ DMSO, they were only visible after $1 \mathrm{~h}$ in the presence of DMSO (de Ménorval et al., 2012). Considering that be used 25 or $50 \mu \mathrm{g} / \mathrm{ml}$ of $\mathbf{B} 2$ to stain cells (involving the presence of 6.25 and $12.5 \% \mathrm{v} / \mathrm{v}$ DMSO, respectively), and shorter times of incubation (i.e., 15 or $30 \mathrm{~min}$ ), we speculate that the DMSO could contribute to the entry of $\mathbf{B} 2$ into epithelial cells, with minimal effects on cell morphology. Nevertheless, the potential impact of the DMSO in cellular compartments, at the concentrations and incubation times proposed in this study for B2 staining protocol, must be explored in future analyses.

\section{B2 Cellular Uptake}

To better understand the $\mathbf{B 2}$ potential as biomarker, we characterized its cellular uptake in epithelial cells. For that, we performed flow cytometry assays of cells stained under three different conditions: (1) Two B2 concentrations that allow cell staining (25 and $50 \mu \mathrm{g} / \mathrm{mL})$; (2) two incubation times with B2: $15 \mathrm{~min}$, suboptimal for staining, and $30 \mathrm{~min}$, optimal for staining; and (3) two temperatures (4 and $37^{\circ} \mathrm{C}$ ). We determined its cellular uptake under the last condition because it is particularly valuable to assess the entry mechanism, since active endocytic processes are inhibited at $4{ }^{\circ} \mathrm{C}$ (Mukherjee et al., 1997). As shown in Figure 3, B2 cellular uptake is dependent on both incubation time and concentration. Although $\mathbf{B 2}$ uptake significantly decreases at $4^{\circ} \mathrm{C}$ compared to the uptake observed at $37^{\circ} \mathrm{C}$, cells still showed considerable B2-dependent luminescence at $4^{\circ} \mathrm{C}$, especially when cells were incubated for $30 \mathrm{~min}$. In fact, the decreased uptake at $4^{\circ} \mathrm{C}$ can be explained by the diminished plasma membrane fluidity, since at low temperatures the diffusion rate is impaired (Cooper and Sunderland, 2000). Since active uptake is inhibited at $4^{\circ} \mathrm{C}$, we infer that $\mathbf{B 2}$ is internalized by cells through passive diffusion. This property explains why B2 staining protocol does not require a permeabilization step, providing a simplified staining method. Other authors reported Ir (III)-based $\left(d^{6}\right)$ compounds as potential biomarkers that were unable to enter cells at $4^{\circ} \mathrm{C}$, even after prolonged incubation periods (more than $2 \mathrm{~h}$ ) (Yin Zhang et al., 2010; Zhang et al., 2010). This fact remarks the $\mathbf{B} 2$ advantages in comparison with other fluorophores, even $d^{6}$ complexes, regarding cell labeling.
A

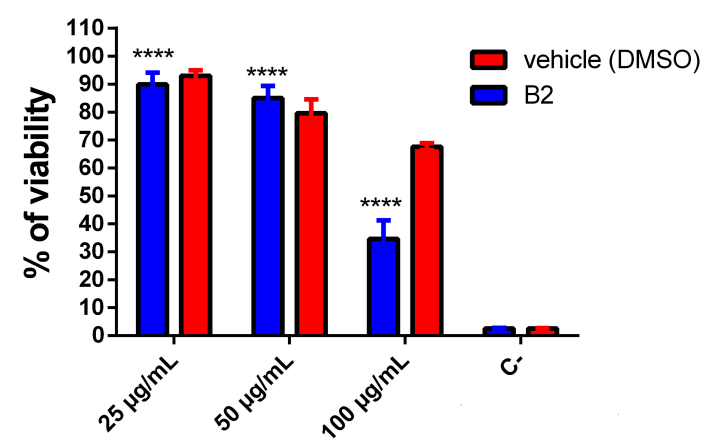

C

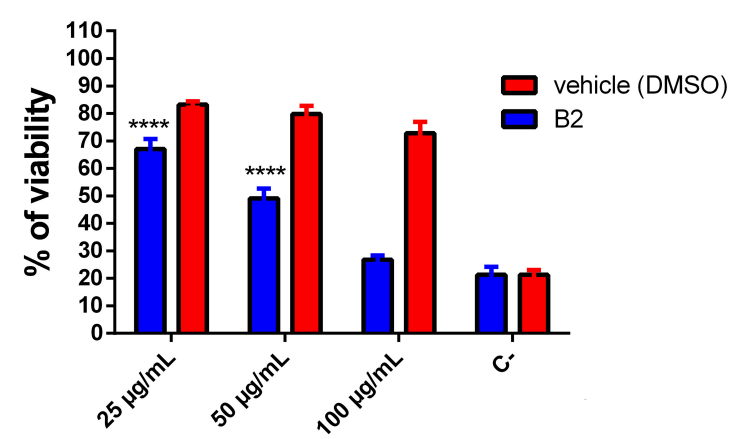

B Cytotoxicity of B2 at $\mathbf{3 0} \mathrm{min}$

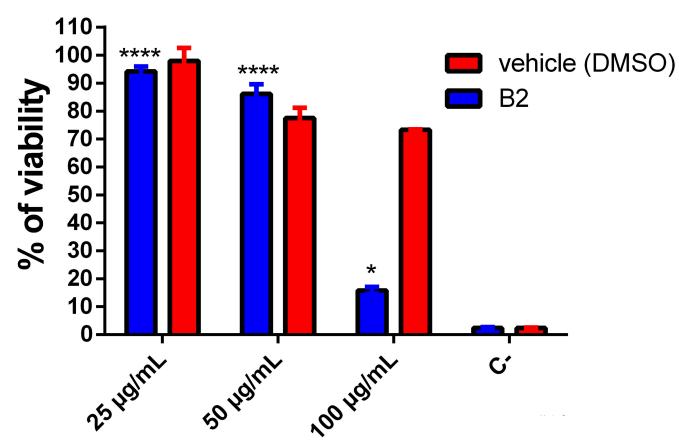

D Cytotoxicity of B2 at 24h

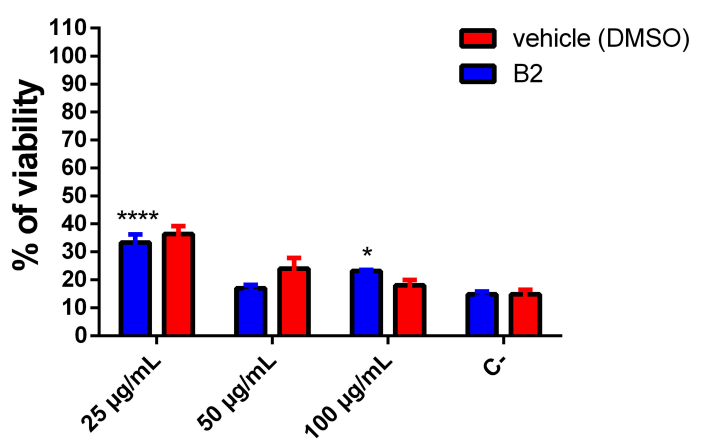

FIGURE 4 | Quantification of B2 cytotoxicity in HeLa cells. Cytotoxicity assay was performed using the MTT Cell Growth Kit. HeLa cells were incubated with B2 $(25 \mu \mathrm{g} / \mathrm{mL}$ or $50 \mu \mathrm{g} / \mathrm{mL})$ for 15 (A), $30 \mathrm{~min}$ (B), 1 (C), and $24 \mathrm{~h}$ (D) at $37^{\circ} \mathrm{C}$. Percentages are corrected based on the viability control (culture medium alone). The significant difference is based on the negative control (DMSO 100\%). A 2-way ANOVA was performed with Tukey's posttest as a statistical analysis. Only relevant differences are depicted in the figure. ${ }^{*} p<0.05,{ }^{\star \star * \star} p<0.0001 . n=3$ (biological triplicate). 
Thus, some of the advantages exhibited by $\mathbf{B} 2$ include its use at low temperatures and low incubation times, valuable properties if considered that not additional permeabilization steps are required.

In general, factors determining the entry of fluorophores into cells include size, charge, and hydrophobicity (Juris et al., 1988; Stufkens, 1998; Puckett and Barton, 2007; Yin Zhang et al., 2010; Zhao et al., 2011; Gill and Thomas, 2012). Thus, B2 might permeate inside cells due to its own chemical nature, by the contribution of the DMSO as an incorporated permeabilizer agent in B2 solutions, or by a combination of this features. Nevertheless, since the DMSO contributes to a slight plasma membrane permeabilization only after $1 \mathrm{~h}$ of incubation at the concentrations used for staining (de Ménorval et al., 2012), we cannot rule out that $\mathbf{B 2}$, itself, is able to penetrate cells by passive transport.
All these properties must be considered to design efficient chemical compounds as cellular biomarkers. Another desirable property for a biomarker is the differential staining. Differential staining is the ability to specifically stain a particular cell structure (e.g., organelles such as endoplasmic reticulum or Golgi apparatus). Normally, biomarkers can be modified to be used as differential dye through conjugation with antibodies, relatively big and complex molecules that usually preclude cell uptake; thereby, additional permeabilization steps are required. By contrast, $\mathbf{B} 2$ provides a simpler method to achieve differential staining without the need of antibodies, as we will discuss below.

\section{B2 Is Suitable as Cellular Biomarker}

A suitable fluorophore for live cell imaging should exhibit three main properties: good and stable luminescence, efficient cellular uptake, and low cytotoxicity (Haas and Franz, 2009).
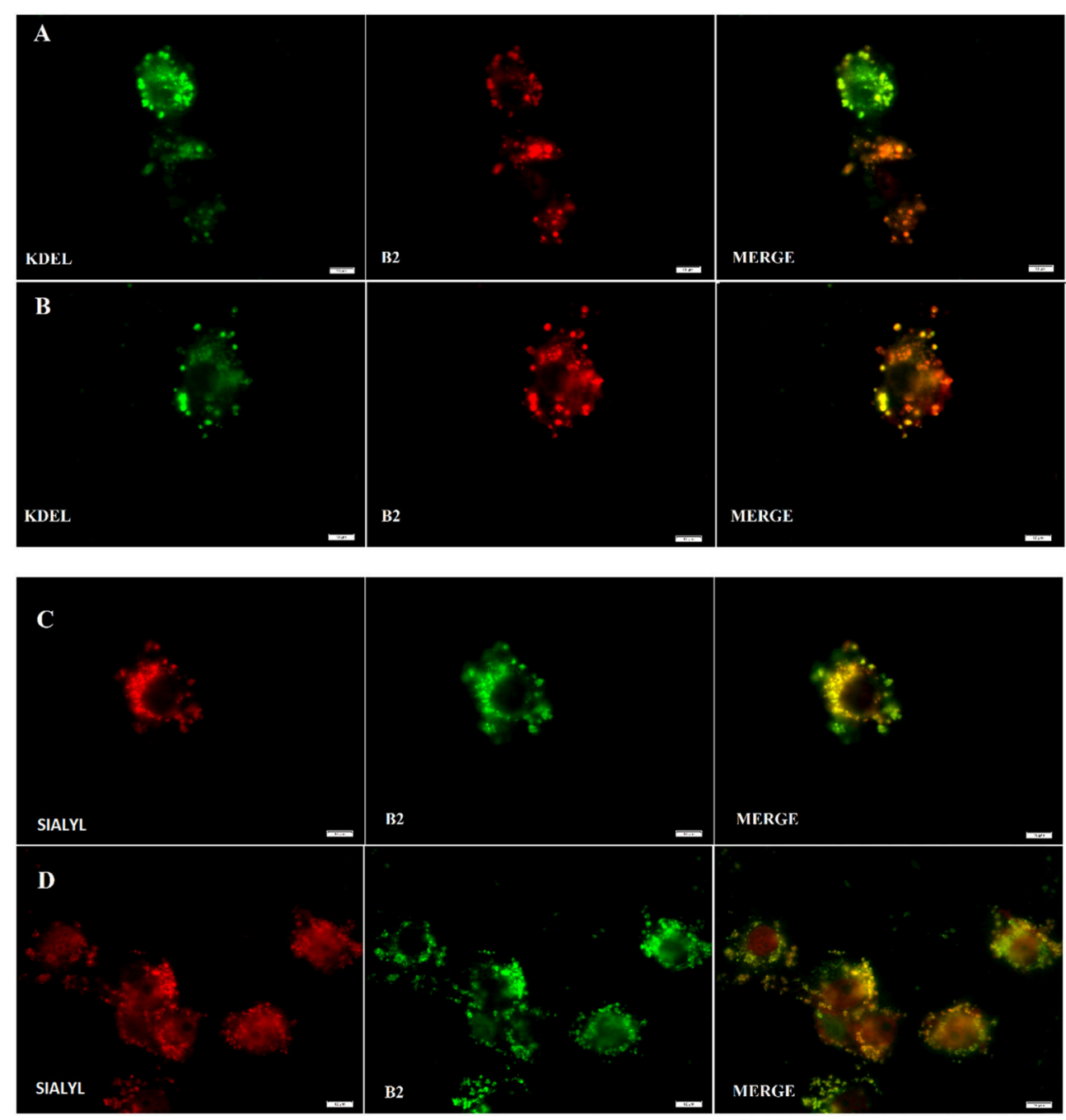

FIGURE 5 | B2 staining co-localizes with Endoplasmic Reticulum (ER) (A,B) and Golgi apparatus (C), (D). Fluorescence assay was performed using HeLa cells and analyzed under fluorescent microscopy at $48 \mathrm{~h}$ post-transfection either with KDEL-GFP gene (A,B) or with Sialyl-RFP (C,D). To stain with B2, respective transfected cells were simply incubated with $\mathbf{B} 2$ at $50 \mu \mathrm{g} / \mathrm{mL}$ for $30 \mathrm{~min}$ at $37^{\circ} \mathrm{C}$. In the case of $\mathbf{B 2}$, a pseudo color was used to facilitate its visualization and co localization. White bars represent $10 \mu \mathrm{m}$. 
In this context, we evaluated B2 cytotoxicity in epithelial cells by MTT assays. MTT is a yellow compound that, when reduced by functioning mitochondria, produces purple formazan crystals that can be measured spectrophotometrically (Low et al., 2016; Sheikh et al., 2016). We tested different concentrations of $\mathbf{B} 2(25,50$, and $100 \mu \mathrm{g} / \mathrm{mL})$ and different incubation times ( $15 \mathrm{~min}, 30 \mathrm{~min}, 1 \mathrm{~h}$, and $24 \mathrm{~h}$ ). It is important to remark that the optimal staining protocol requires $50 \mu \mathrm{g} / \mathrm{mL}$ of B2, and $30 \mathrm{~min}$ of incubation (Figure 2). Figures 4A,B show that, at the staining conditions, B2 presented low cytotoxicity (around 10\%) compared with the vehicle alone (i.e., DMSO), values that represent no toxicity for cellular models (Nel et al., 2009). By contrast, more prolonged incubation times, or higher concentrations, produced more pronounced effects (Figures 4C,D). In these cases, cytotoxicity increased by approximately $33 \%$ at $1 \mathrm{~h}$ incubation time using $25 \mu \mathrm{g} / \mathrm{mL}$, and at $52 \%$ using $50 \mu \mathrm{g} / \mathrm{mL}$, which can be due to an excessive accumulation of $\mathbf{B 2}$ in organelles and to the presence of DMSO (vehicle). DMSO increases cyclic adenosine monophosphate (cAMP), a second messenger involved in cell death by apoptosis (Cho et al., 2014). These results indicate that $\mathbf{B} 2$ can be used in living systems as biomarker at relatively short incubation times (15 to $30 \mathrm{~min}$ ), whereas more prolonged times (i.e., $>1 \mathrm{~h}$ ) are not recommended due to higher cytotoxicity levels, not biocompatible for these kind of studies (i.e., >20\%) (Nel et al., 2009). These results show that B2 exhibited low cytotoxicity under the staining conditions proposed in this work, proving its biocompatibility as biomarker.

\section{B2 Accumulates in Endoplasmic Reticulum and Golgi Apparatus}

As shown in Figure 2, B2 presented a punctuate staining pattern, with a central unstained area plausibly corresponding to the cell nucleus. This strongly suggests that B2 is accumulated in a discrete, particular cell structure (e.g., an organelle). It has been reported that endoplasmic reticulum (ER) exhibit a similar staining pattern (Li et al., 2016). The ER and Golgi apparatus are two organelles that work together in the secretory pathway of eukaryotic proteins (Hanada, 2017). Thus, we proposed that $\mathbf{B} \mathbf{2}$ is being accumulated in these organelles. To test this hypothesis, we performed co-localization experiments using known intracellular fluorescent markers normally used as reference: KDEL-GFP [lysine/aspartate/glutamate/leucine-green fluorescent protein (emission: 503-508 nm)], to stain the ER; and Sialyl-RFP [Sialyl transferase signal anchor sequence-red fluorescent protein $(583 \mathrm{~nm})$ ], to stain the Golgi apparatus (Tsien, 1998; Dayel et al., 1999; Remington, 2002; Hawes and SatiatJeunemaitre, 2005). These reference biomarkers, i.e., KDELGFP and Sialyl-RFP, are recombinant fluorescent proteins that accumulates in secretory organelles. As described above, the staining protocol of $\mathbf{B} \mathbf{2}$ is simple, consisting mainly in short incubation times (30 min). Unlike B2, KDEL-GFP and SialylRFP need to be expressed directly by the cells, thereby a transfection protocol must be performed. Transfection consists in introducing purified nucleic acids, normally produced in bacteria, into eukaryotic cells to express heterologous proteins, such as KDEL-GFP or sialyl-RFP. Complete transfection protocol can take two or more days.
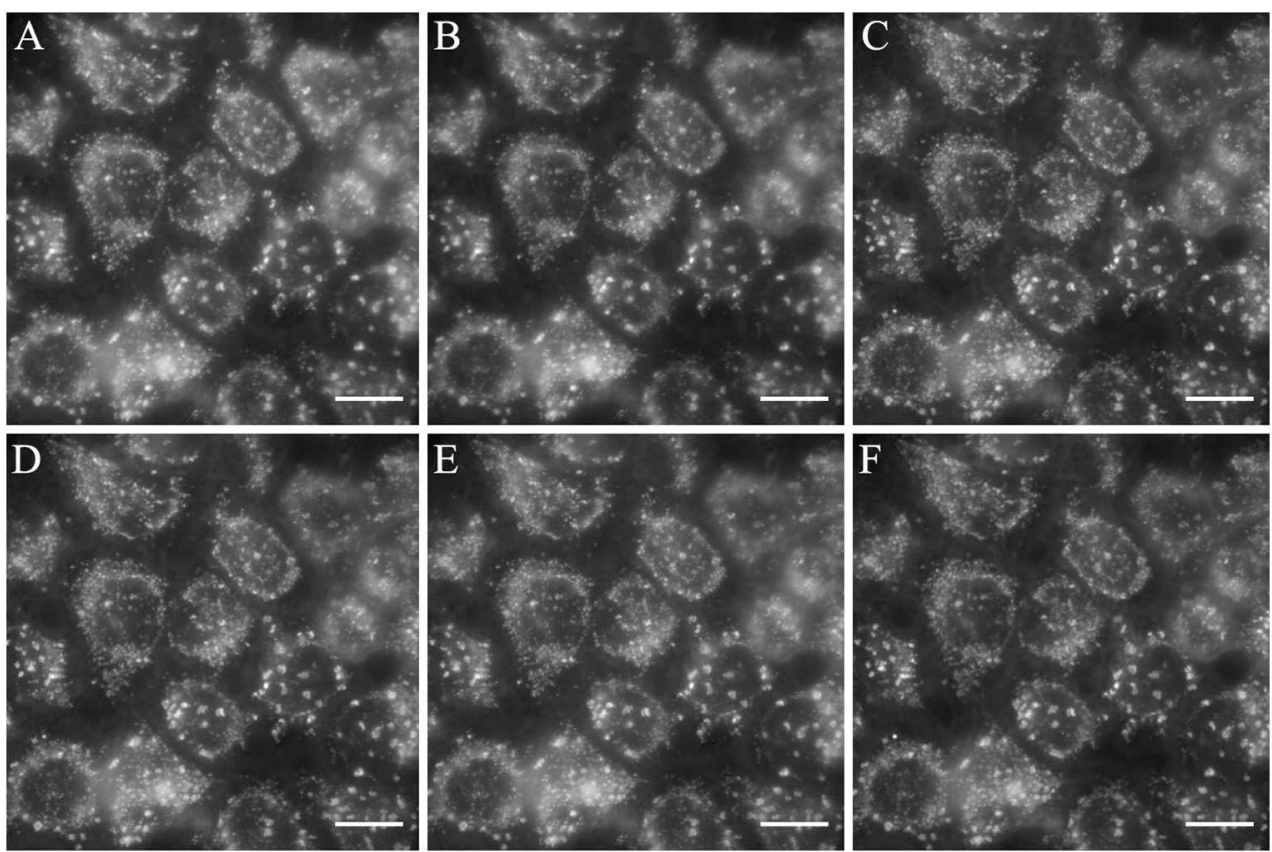

FIGURE 6 | B2 exhibits resistance to photobleaching. HeLa cells were stained with $50 \mu \mathrm{g} / \mathrm{mL} \mathbf{B 2}$ for 30 min at $37^{\circ} \mathrm{C}$ and observed under the fluorescent microscope immediately (A), or $5 \mathrm{~min}$ (B), $10 \mathrm{~min}$ (C), $15 \mathrm{~min}$ (D), $30 \mathrm{~min}$ (E), $60 \mathrm{~min}$ (F) after the staining protocol in continuous exposure to the exciting light. We obtained similar results with MCF-7 cells (data not shown). Blinking was not observed (see Supplementary Video 1). White bar represents $10 \mu \mathrm{m}$. 
As shown in Figure 5, B2 accumulates in subcellular compartments from the secretory pathways (i.e., ER and Golgi apparatus), revealing these organelles as efficiently as KDELGFP or Sialyl-RFP, but with a simpler method. B2 accumulation in the ER and in the Golgi apparatus is probably due to its affinity for certain proteins inside these organelles, probably glycoproteins. Zhang et al. demonstrated that two fluorophores based on Ir (III) present high affinity for the Golgi apparatus (Zhang et al., 2010). These Ir (III)-based compounds possess many pyridine groups, which are also present in the $\mathbf{B} 2$ structure. Nevertheless, comparing B2 and Ir (III)-based fluorophores, B2 is a simpler molecule exhibiting better quantum yields ( $\varphi=0.21$ in acetonitrile) (Carreño et al., 2016), whereas Ir (III)-based fluorophores are complex dendritic cyclometalated compounds exhibiting lower quantum yields $(\phi=0.036$ to 0.14 in acetonitrile, depending on the compound). Most importantly, visualization of Golgi apparatus in HeLa cells requires $2 \mathrm{~h}$ of incubation with $2 \mathrm{M}$ of Ir (III) complexes to obtain similar results (Zhang et al., 2010) to those shown in the Figure 5, which needed lower incubation time at lower concentration $(155 \mu \mathrm{M})$ of B2. Furthermore, although other fluorophores have been reported to stain the ER, such as the ER-tracker $\left(\mathrm{C}_{44} \mathrm{H}_{42} \mathrm{BClF}_{2} \mathrm{~N}_{6} \mathrm{O}_{7} \mathrm{~S}_{2}\right)$, (ThermoFisher ${ }^{1}$; Diwu et al., 1997) their considerable size mandatorily requires cell permeabilization, a step that is not necessary in the case of the $\mathbf{B} \mathbf{2}$ staining protocol.

On the other hand, it has been reported that $\operatorname{DiOC}_{6}(3)$ is able to stain the $\mathrm{ER}$ at $10 \mu \mathrm{g} / \mathrm{mL}$. Nevertheless, at lower concentrations (i.e., $0.1 \mu \mathrm{g} / \mathrm{mL}$ ), $\mathrm{DiOC}_{6}(3)$ stains mitochondria instead, letting unclear which are the limit concentrations to stain one organelle or another (Sabnis et al., 2009). By contrast, B2 stain ER and Golgi at $50 \mu \mathrm{g} / \mathrm{mL}$ (or more), whereas lower concentrations appear to be unable to stain (as mentioned above), allowing a better identification.

Thus, unlike other fluorophores which only have cytoplasmic or perinuclear distribution (Puckett and Barton, 2007; Yin Zhang et al., 2010; Zhang et al., 2010), B2 provides a simple and efficient way to differentially stain ER and Golgi apparatus in epithelial cells, showing that $\mathbf{B} 2$ can be considered a differential fluorescent dye.

\section{Blinking and Bleaching B2 Properties}

Some fluorophores exhibit unpredictable blinking properties, a clear drawback to obtain high quality images (Michalet et al., 2005; Mahler et al., 2008). On the other hand, photobleaching is also an undesired property of fluorophores when time-lapse experiments or videos under continuous exposure are required (Li et al., 2017; Elisa et al., 2018). For instance, $\operatorname{DiOC}_{6}(3)$ exhibits photobleaching similar to that of the rhodamine (Sabnis et al., 2009). To test whether B2 exhibits photobleaching and/or blinking in biological applications, we stained HeLa cells with $50 \mu \mathrm{g} / \mathrm{mL} \mathrm{B2}$ for $30 \mathrm{~min}$ at $37^{\circ} \mathrm{C}$. Then, stained cells were observed by fluorescence microscopy during $1 \mathrm{~h}$ with continuous exposure. As shown in Figure 6, B2 is resistant to photobleaching, and blinking was not observed (see Supplementary Video 1). This phenomenon can be explained by the high stability of $\mathbf{B 2}$, as demonstrated above. The IHB, that is stable in different organic solvents (Table S2), contributes to keep the rigidity between the benzimidazole and phenolic ring moieties, substantially reducing the vibronic relaxation due to a coplanar geometry between the rings, and contributing to the fluorescence by minimizing the non-radiative emission. All this evidence suggests that, at least in part, the presence of a stable IHB contributes to strongly decrease photobleaching of $\mathbf{B 2}$.

\section{CONCLUSIONS}

In this work, we explored new features of the luminescent compound B2 concerning some of its chemical properties, and its use as biomarker for specific cell organelles. We found that B2 exhibits a very stable structure, a feature that in turn contributes to a photobleaching-resistant fluorescence. In addition, B2 provides a rapid (30 min for optimal staining), simple (since no cell permeabilization is required), biocompatible (low cytotoxicity under staining conditions), and efficient way to fluorescently label both ER and Golgi apparatus, producing similar results to that obtained with other well-established methods, but without photobleaching or blinking. Altogether, our results show that $\mathbf{B} 2$ is suitable to be used for differential labeling of ER and Golgi apparatus, in time-lapse experiments or short videos with continuous exposure, even at low temperatures.

\section{DEDICATION}

Dedicated to Professor Juan Manuel Manríquez on the occasion of his retirement.

\section{AUTHOR CONTRIBUTIONS}

FL: Cytotoxicity and uptake experiment, discussion of biological experiment and paper writing; JF: Discussion of all the experiments, and paper writing; AC: Synthesis, characterization, discussion of all the experiments, and paper writing; CZ: Optical and other chemical characterizations; DP-H: Theoretical calculations; MG: Electrochemical studies; RP: Discussion of Biological experiments; MP: Discussion of NMR, TOCSY and FTIR experiments; RA-P: Discussion of theoretical calculations; CO: Microscopy and discussion of Biological experiments.

\section{FUNDING}

This work was funded by FONDECYT 11170637 and Proyecto Núcleo UNAB DI-1419-16/N.

\section{ACKNOWLEDGMENTS}

JF thanks FONDECYT 1181638, DP-H thanks FONDECYT 11140294, RA-P thanks FONDECYT 1150629, MG thanks FONDECYT 11170300. We are grateful to Dr. María Angélica del Valle (UC), and Dr. Ivonne Chávez (UC) for instrumental facilities. Also, we thank Beatriz Álvarez and Alfonso Inzunza for his help for the English usage. 


\section{SUPPLEMENTARY MATERIAL}

The Supplementary Material for this article can be found online at: https://www.frontiersin.org/articles/10.3389/fchem. 2018.00345/full\#supplementary-material

Figure S1 | Molecular model of pyridine benzimidazole 2,4-di-tert-butyl-6-(3H-imidazo[4,5-c]pyridine-2-yl)phenol (B2) used in this study; front (A) and slide (B)

Figure S2 | FTIR (ATR) of precursor (phenyl-3,5-di-tert-butyl-2-hydroxybenzoate).

Figure S3 | FTIR (ATR) of B2.

Figure S4 | Numbering protons of B2.

Figure S5 | Aromatic zone of the ${ }^{1} \mathrm{HNMR}$ spectrum of $\mathbf{B 2}$.

Figure S6 | 1D TOCSY of B2 (in DMSO-d6), irradiating H3 at 3,597 Hz (8.99 ppm). Figure S7 | 1D TOCSY of B2 (in DMSO-d6), irradiating H4 at 3,208 Hz (8.02 ppm). Figure S8 | 1D TOCSY of B2 (in DMSO-d6), irradiating $-\mathrm{OH}$ at $5,451 \mathrm{~Hz}(13.62$ ppm).

\section{REFERENCES}

Abdel Ghani, N. T., and Mansour, A. M. (2012). Molecular structures of 2-arylaminomethyl-1H-benzimidazole: spectral, electrochemical, DFT and biological studies. Spectrochim Acta A Mol. Biomol. Spectrosc. 91, 272-284.doi: 10.1016/j.saa.2012.01.080

Alvarado-Soto, L., and Ramirez-Tagle, R. (2015). A theoretical study of the binding of $\left[\mathrm{Re}_{6} \mathrm{Se}_{8}(\mathrm{OH})_{2}\left(\mathrm{H}_{2} \mathrm{O}\right)_{4}\right]$ rhenium clusters to DNA purine base guanine. Materials 8, 3938-3944. doi: 10.3390/ma8073938

Atale, N., Gupta, S., Yadav, U. C., and Rani, V. (2014). Cell-death assessment by fluorescent and nonfluorescent cytosolic and nuclear staining techniques. J. Microsc. 255, 7-19. doi: 10.1111/jmi.12133

Avilés-Moreno, J. R., Berden, G., Oomens, J., and Martinez-Haya, B. (2017). Isolated complexes of the amino acid arginine with polyether and polyamine macrocycles, the role of proton transfer. Phys. Chem. Chem. Phys. 19, 31345-31351. doi: 10.1039/c7cp04270a

Benisvy, L., Bill, E., Blake, A. J., Collison, D., Davies, E. S., Garner, C. D., et al. (2006). Phenoxyl radicals: H-bonded and coordinated to $\mathrm{Cu}$ (II) and $\mathrm{Zn}$ (II). Dalton Trans. 2006, 258-267. doi: 10.1039/b513221p

Berríos, P., Fuentes, J. A., Salas, D., Carreno, A., Aldea, P., Fernandez, F., et al. (2017). Inhibitory effect of biofilm-forming Lactobacillus kunkeei strains against virulent Pseudomonas aeruginosa in vitro and in honeycomb moth (Galleria mellonella) infection model. Benef. Microbes 9, 257-268. doi: 10.3920/BM2017.0048

Bielaszewska, M., Rüter, C., Bauwens, A., Greune, L., Jarosch, K. A., Steil, D., et al. (2017). Host cell interactions of outer membrane vesicle-associated virulence factors of enterohemorrhagic Escherichia coli O157: intracellular delivery, trafficking and mechanisms of cell injury. PLoS Pathog. 13:e1006159. doi: 10.1371/journal.ppat.1006159

Bielaszewska, M., Rüter, C., Kunsmann, L., Greune, L., Bauwens, A., Zhang, W., et al. (2013). Enterohemorrhagic Escherichia coli hemolysin employs outer membrane vesicles to target mitochondria and cause endothelial and epithelial apoptosis. PLoS Pathog. 9:e10 03797. doi: 10.1371/journal.ppat.1003797

Bjorgaard, J. A., Velizhanin, K. A., and Tretiak, S. (2015). Solvent effects in time-dependent self-consistent field methods. II. Variational formulations and analytical gradients. J. Chem. Phys. 143:054305. doi: 10.1063/1.4927167

Boiani, M., Boiani, L., Denicola, A., Torres De Ortiz, S., Serna, E., Vera De Bilbao, N., et al. (2006). 2H-benzimidazole 1,3-dioxide derivatives: a new family of water-soluble anti-trypanosomatid agents. J. Med. Chem. 49, 3215-3224. doi: $10.1021 /$ jm0600343

Cañas, M. A., Giménez, R., Fábrega, M. J., Toloza, L., aldomà, L., and Badia, J. (2016). Outer membrane vesicles from the probiotic Escherichia coli Nissle
Figure S9 | UV-Vis spectrum of B2 in chloroform, acetonitrile and DMSO at room temperature.

Figure S10 | Scan-rate study for B2. Interphase: Pt|1.0.10 ${ }^{-2}$ M B2 $+1.0 \cdot 10^{-1}$ $\mathrm{M} \mathrm{TBAPF}_{6}$ in anhydrous $\mathrm{CH}_{3} \mathrm{CN}$.

Table S1 | Characteristic constants of phenyl-3,5-di-tert-butyl-2-hydroxybenzoate* and B2.

Table S2 | UV-Vis absorption spectra of B2 in different organic solvents at room temperature.

Table S3 | Scan-rate study for determining diffusional control of described electrochemical processes at B2.

Table S4 | Results for the geometry optimization of the ground (SO) and first excited singlet (S1) state.

Table S5 | The most important absorption and emission bands for B2 in DMSO.

Supplementary Video 1 | HeLa cells were seeded on coverslips and incubated with $50 \mu \mathrm{g} / \mathrm{mL}$ of $\mathrm{B} 2$ for $30 \mathrm{~min}$ at $37^{\circ} \mathrm{C}$. Then, cells were observed under fluorescent microscope with constant exposure of $350 \mathrm{msec}$.

1917 and the commensal ECOR12 enter intestinal epithelial cells via clathrindependent endocytosis and elicit differential effects on DNA damage. PLoS ONE 11:e0160374. doi: 10.1371/journal.pone.0160374

Carreño, A., Gacitúa, M., Fuentes, J. A., Páez-Hernández, D., Araneda, C., Chávez, I., et al. (2016). Theoretical and experimental characterization of a novel pyridine benzimidazole: suitability for fluorescence staining in cells and antimicrobial properties. New J. Chem. 40, 2362-2375. doi: 10.1039/C5NJ02772A

Carreño, A., Solis-Céspedes, E., Páez-Hernández, D., and Arratia-Pérez, R. (2017). Exploring the geometrical and optical properties of neutral rhenium (I) tricarbonyl complex of 1,10-phenanthroline-5,6-diol using relativistic methods. Chem. Phys. Lett. 685, 354-362. doi: 10.1016/j.cplett.2017.07.058

Cho, E. A., Kim, E. J., Kwak, S. J., and Juhnn, Y. S. (2014). cAMP signaling inhibits radiation-induced ATM phosphorylation leading to the augmentation of apoptosis in human lung cancer cells. Mol. Cancer 13:36. doi: 10.1186/1476-4598-13-36

Cooper, G. M. (2000). The Cell: A Molecular Approach. Boston, MA: Boston University.

Cooper, G. M., and Sunderland, M. A. (2000). The Cell: A Molecular Approach. Boston, MA.

Dayel, M. J., Hom, E. F., and Verkman, A. S. (1999). Diffusion of green fluorescent protein in the aqueous-phase lumen of endoplasmic reticulum. Biophys. J. 76, 2843-2851.

de Ménorval, M. A., Mir, L. M., Fernandez, M. L., and Reigada, R. (2012). Effects of dimethyl sulfoxide in cholesterol-containing lipid membranes: a comparative study of experiments in silico and with cells. PLoS ONE 7:e41733. doi: 10.1371/journal.pone.0041733

Diwu, Z., Lu, Y., Zhang, C., Klaubert, D. H., and Haugland, R. P. (1997). Fluorescent molecular probes II. The synthesis, spectral properties and use of fluorescent solvatochromic dapoxyl dyes. Photochem. Photobiol. 66, 424-431.

Echeverria, C., Santibanez, J. F., Donoso-Tauda, O., Escobar, C. A., and Ramirez-Tagle, R. (2009). Structural antitumoral activity relationships of synthetic chalcones. Int. J. Mol. Sci. 10, 221-231. doi: 10.3390/ijms10 010221

Elisa, Z., Toon, B., De Smedt, S. C., Katrien, R., Kristiaan, N., and Kevin, B. (2018). Technical implementations of light sheet microscopy. Microsc. Res. Tech. doi: 10.1002/jemt.22981. [Epub ahead of print].

Fuks, J. I., Elliott, P., Rubio, A., and Maitra, N. T. (2013). Dynamics of chargetransfer processes with time-dependent density functional theory. J. Phys. Chem. Lett. 4, 735-739. doi: 10.1021/jz302099f

Ghane, T., Brancolini, G., Varsano, D., and Di Felice, R. (2012). Optical properties of triplex DNA from time-dependent density functional theory. J. Phys. Chem. B 116, 10693-10702. doi: 10.1021/jp304818s 
Gill, M. R., and Thomas, J. A. (2012). Ruthenium(II) polypyridyl complexes and DNA-from structural probes to cellular imaging and therapeutics. Chem. Soc. Rev. 41, 3179-3192. doi: 10.1039/c2cs15299a

Gopal, V. R., Reddy, A. M., and Rao, V. J. (1995). Wavelength-dependent trans to cis and quantum chain isomerizations of anthrylethylene derivatives. J. Organ. Chem. 60, 7966-7973.

Guajardo Maturana, R., Valenzuela, M. L., Schott, E., and Rojas-Poblete, M. (2017). Bonding and optical properties of spirocyclic-phosphazene derivatives. A DFT approach. Phys. Chem. Chem. Phys. 19, 31479-31486. doi: 10.1039/c7cp06064e

Haas, K. L., and Franz, K. J. (2009). Application of metal coordination chemistry to explore and manipulate cell biology. Chem. Rev. 109, 4921-4960. doi: $10.1021 / \mathrm{cr} 900134 \mathrm{a}$

Hanada, K. (2017). Ceramide transport from the endoplasmic reticulum to the trans golgi region at organelle membrane contact sites. Adv. Exp. Med. Biol. 997, 69-81. doi: 10.1007/978-981-10-4567-7_5

Hawes, C., and Satiat-Jeunemaitre, B. (2005). The plant Golgi apparatus-going with the flow. Biochim. Biophys. Acta 1744, 93-107. doi: 10.1016/j.bbamcr.2005.03.009

Juris, A., Balzani, V., Barigelletti, F., Campagna, S., Belser, P., and Von Zelewsky, A. (1988). $\mathrm{Ru}(\mathrm{II})$ polypyridine complexes: photophysics, photochemistry, eletrochemistry, and chemiluminescence. Coord. Chem. Rev. 84, 85-277.

Kingston, R. E., Chen, C. A., and Okayama, H. (2001). Calcium phosphate transfection. Curr. Protoc. Immunol. 31, 10.13.1-10.13.9. doi: $10.1002 / 0471142735$.im1013s31

Li, J. F., Li, C. Y., and Aroca, R. F. (2017). Plasmon-enhanced fluorescence spectroscopy. Chem. Soc. Rev. 46, 3962-3979.doi: 10.1039/C7CS00169J

Li, K. T., Chen, Q., Wang, D. W., Duan, Q. Q., Tian, S., He, J. W., et al. (2016). Mitochondrial pathway and endoplasmic reticulum stress participate in the photosensitizing effectiveness of AE-PDT in MG63 cells. Cancer Med. 5, 3186-3193. doi: $10.1002 / \mathrm{cam} 4.895$

Liu, Y. F., Yang, D. P., Shi, D. H., and Sun, J. F. (2011). A TD-DFT study on the hydrogen bonding of three esculetin complexes in electronically excited states: strengthening and weakening. J. Comput. Chem. 32, 3475-3484. doi: $10.1002 / j c c .21932$

Low, M. L., Maigre, L., Tahir, M. I., Tiekink, E. R., Dorlet, P., Guillot, R., et al. (2016). New insight into the structural, electrochemical and biological aspects of macroacyclic $\mathrm{Cu}$ (II) complexes derived from S-substituted dithiocarbazate schiff bases. Eur. J. Med. Chem. 120, 1-12. doi: 10.1016/j.ejmech.2016. 04.027

Mahler, B., Spinicelli, P., Buil, S., Quelin, X., Hermier, J. P., and Dubertret, B. (2008). Towards non-blinking colloidal quantum dots. Nat. Mater. 7, 659-664. doi: $10.1038 /$ nmat 2222

Manbeck, G. F., Fujita, E., and Concepcion, J. J. (2016). Proton-coupled electron transfer in a strongly coupled photosystem ii-inspired chromophoreimidazole-phenol complex: stepwise oxidation and concerted reduction. J. Am. Chem. Soc. 138, 11536-11549. doi: 10.1021/jacs.6b03506

Michalet, X., Pinaud, F. F., Bentolila, L. A., Tsay, J. M., Doose, S., Li, J. J., et al. (2005). Quantum dots for live cells, in vivo imaging, and diagnostics. Science 307, 538-544. doi: 10.1126/science.1104274

Monajjemi, M. (2012). NMR and NBO calculation of benzimidazoles and pyrimidines: nano physical parameters investigation. Int. J. Phys. Sci. 7, 2010-2031. doi: 10.5897/IJPS11.507

Moore, G. F., Hambourger, M., Gervaldo, M., Poluektov, O. G., Rajh, T., Gust, D., et al. (2008). A bioinspired construct that mimics the proton coupled electron transfer between $\mathrm{P} 680^{*}+$ and the $\operatorname{Tyr}(\mathrm{Z})$-His 190 pair of photosystem II. J. Am. Chem. Soc. 130, 10466-10467. doi: 10.1021/ja803015m

Moore, G. F., Hambourger, M., Kodis, G., Michl, W., Gust, D., Moore, T. A., et al. (2010). Effects of protonation state on a tyrosine-histidine bioinspired redox mediator. J. Phys. Chem. B 114, 14450-14457. doi: 10.1021/jp101592m

Mosquera, M. A., and Wasserman, A. (2015). Time-dependent electronic populations in fragment-based time-dependent density functional theory. J. Chem. Theory Comput. 11, 3530-3536. doi: 10.1021/acs.jctc.5b00342

Muhammad, S., Xu, H., Janjua, M. R., Su, Z., and Nadeem, M. (2010). Quantum chemical study of benzimidazole derivatives to tune the second-order nonlinear optical molecular switching by proton abstraction. Phys. Chem. Chem. Phys. 12, 4791-4799.doi: 10.1039/B924241D

Mukherjee, S., Ghosh, R. N., and Maxfield, F. R. (1997). Endocytosis. Physiol. Rev. $77,759-803$.
Nel, A. E., Mädler, L., Velegol, D., Xia, T., Hoek, E. M., Somasundaran, P., et al. (2009). Understanding biophysicochemical interactions at the nano-bio interface. Nat. Mater. 8, 543-557. doi: 10.1038/nmat2442

Puckett, C. A., and Barton, J. K. (2007). Methods to explore cellular uptake of ruthenium complexes. J. Am. Chem. Soc. 129, 46-47. doi: 10.1021/ja06 77564

Quartarolo, A. D., and Russo, N. (2011). A computational study (TDDFT and RICC2) of the electronic spectra of pyranoanthocyanins in the gas phase and solution. J. Chem. Theory. Comput. 7, 1073-1081. doi: 10.1021/ct20 00974

Rabanal-Leon, W. A., Murillo-Lopez, J. A., Paez-Hernandez, D., and Arratia-Perez, R. (2014). Understanding the influence of terminal ligands on the electronic structure and bonding nature in [Re6(mu3-Q8)](2+) clusters. J. Phys. Chem. A 118, 11083-11089. doi: 10.1021/jp508892r

Ramírez-Tagle, R., Alvarado-Soto, L., Hernández-Acevedo, L., and Arratia-Pérez, R. (2010). Spin-orbit and solvent effects in the luminescent [Re6Q8(NCS)6]4-, $\mathrm{Q}=\mathrm{S}$, se, Te clusters: molecular sensors and molecular devices. J. Chilean Chem. Soc. 55, 39-43. doi: 10.4067/s0717-97072010000100010

Remington, S. J. (2002). Negotiating the speed bumps to fluorescence. Nat. Biotechnol. 20, 28-29. doi: 10.1038/nbt0102-28

Sabnis, R. W., Deligeorgiev, T. G., Jachak, M. N., and Dalvi, T. S. (1997). DiOC6(3): a useful dye for staining the endoplasmic reticulum. Biotech. Histochem. 72, 253-258.

Sabnis, R. W., Deligeorgiev, T. G., Jachak, M. N., and Dalvi, T. S. (2009). DiOC6(3): a useful dye for staining the endoplasmic reticulum. Biotech. Histochem. 72, 253-258.doi: 10.3109/10520299709082249

Sanderson, M. J., Smith, I., Parker, I., and Bootman, M. D. (2014). Fluorescence microscopy. Cold Spring Harb. Protoc. 2014:pdb top071795. doi: 10.1101/pdb.top071795

Savarino, P., Viscardi, G., Quagliotto, P., Perracino, P., and Barni, E. (1997). Voltammetric behaviour of heterocyclic systems. Pyridyl-substituted benzimidazoles, benzoxazoles and benzothiazoles.1. J. Heterocyclic Chem. 34, 1479-1485.

Sheikh, R. A., Wani, M. Y., Shreaz, S., and Hashmi, A. A. (2016). Synthesis, characterization and biological screening of some Schiff base macrocyclic ligand based transition metal complexes as antifungal agents. Arabian J. Chem. 9, S743-S751. doi: 10.1016/j.arabjc.2011.08.003

Simpson, S., Gross, M. S., Olson, J. R., Zurek, E., and Aga, D. S. (2015). Identification of polybrominated diphenyl ether metabolites based on calculated boiling points from COSMO-RS, experimental retention times, and mass spectral fragmentation patterns. Anal. Chem. 87, 2299-2305. doi: $10.1021 /$ ac504107b

Sinnecker, S., Rajendran, A., Klamt, A., Diedenhofen, M., and Neese, F. (2006). Calculation of solvent shifts on electronic g-tensors with the conductorlike screening model (COSMO) and its self-consistent generalization to real solvents (direct COSMO-RS). J. Phys. Chem. A 110, 2235-2245. doi: $10.1021 /$ jp056016z

Sosa, G. L., Peruchena, N. M., Contreras, R. H., and Castro, E. A. (2002). Topological and NBO analysis of hydrogen bonding interactions involving C-H...O bonds. J. Mol. Struc. 577, 219-228. doi: 10.1016/s0166-1280(01)0 0670-4

Stufkens, D. (1998). Ligand-dependent excited state behaviour of $\operatorname{Re}(\mathrm{I})$ and $\mathrm{Ru}(\mathrm{II})$ carbonyl-diimine complexes. Coord. Chem. Rev. 177, 127-179.

Te Velde, G., Bickelhaupt, F. M., Baerends, E. J., Fonseca Guerra, C., Van Gisbergen, S. J. A., Snijders, J. G., et al. (2001). Chemistry with ADF. J. Comput. Chem. 22, 931-967. doi: 10.1002/jcc. 1056

Tsien, R. Y. (1998). The green fluorescent protein. Аnnu. Rev. Biochem. 67, 509-544.

Tsolakidis, A., and Kaxiras, E. (2005). A TDDFT study of the optical response of DNA bases, base pairs, and their tautomers in the gas phase. J. Phys. Chem. A 109, 2373-2380. doi: 10.1021/jp044729w

Watson, P., Jones, A. T., and Stephens, D. J. (2005). Intracellular trafficking pathways and drug delivery: fluorescence imaging of living and fixed cells. $A d v$. Drug Deliv. Rev. 57, 43-61. doi: 10.1016/j.addr.2004.05.003

Wollman, A. J., Nudd, R., Hedlund, E. G., and Leake, M. C. (2015). From Animaculum to single molecules: 300 years of the light microscope. Open Biol. 5:150019. doi: 10.1098/rsob.150019 
Yamin, P., Isele-Holder, R., and Leonhard, K. (2016). Predicting octanol/water partition coefficients of alcohol ethoxylate surfactants using a combination of molecular dynamics and the conductor-like screening model for realistic solvents. Ind. Eng. Chem. Res. 55, 4782-4789. doi: 10.1021/acs.iecr.5b04955

Yankova, R., and Radev, L. (2016). Structural and electronic properties of $\left.[\mathrm{Co} \text { (benzimidazole })_{2} \mathrm{I}_{2}\right]$. Int. J. Mater. Chem. 6, 19-27. doi:10.5923/j.ijmc.20160602.01

Yin Zhang, K., Law, W., and Lo, K. K. (2010). Cyclometalated iridium(III) bipyridine complexes functionalized with an n-methylamino-oxy group as novel phosphorescent labeling reagents for reducing sugars. Organometallics 29, 3474-3476. doi: 10.1021/om100597g

Zhang, D., Zhao, L., Zhu, Y., Li, A., He, C., Yu, H., et al. (2016). Effects of p-(Trifluoromethoxy)benzyl and p-(Trifluoromethoxy)phenyl molecular architecture on the performance of naphthalene tetracarboxylic diimide-based air-stable n-type semiconductors. ACS Appl. Mater. Interfaces 8, 18277-18283. doi: 10.1021/acsami.6b04753

Zhang, K. Y., Liu, H. W., Fong, T. T., Chen, X. G., and Lo, K. K. (2010). Luminescent dendritic cyclometalated iridium(III) polypyridine complexes: synthesis, emission behavior, and biological properties. Inorg. Chem. 49, 5432-5443. doi: 10.1021/ic902443e

Zhao, Q., Huang, C., and Li, F. (2011). Phosphorescent heavy-metal complexes for bioimaging. Chem. Soc. Rev. 40, 2508-2524. doi: 10.1039/c0cs $00114 \mathrm{~g}$

Conflict of Interest Statement: The authors declare that the research was conducted in the absence of any commercial or financial relationships that could be construed as a potential conflict of interest.

Copyright (C) 2018 Llancalahuen, Fuentes, Carreño, Zúñiga, Páez-Hernández, Gacitúa, Polanco, Preite, Arratia-Pérez and Otero. This is an open-access article distributed under the terms of the Creative Commons Attribution License (CC BY). The use, distribution or reproduction in other forums is permitted, provided the original author(s) and the copyright owner(s) are credited and that the original publication in this journal is cited, in accordance with accepted academic practice. No use, distribution or reproduction is permitted which does not comply with these terms. 